\title{
Effectiveness of a multicomponent self-management intervention for adults with epilepsy (ZMILE study)
}

Citation for published version (APA):

Leenen, L. A. M., Wijnen, B. F. M., Kessels, A. G. H., Chan, H., de Kinderen, R. J. A., Evers, S. M. A. A., van Heugten, C. M., \& Majoie, M. H. J. M. (2018). Effectiveness of a multicomponent self-management intervention for adults with epilepsy (ZMILE study): A randomized controlled trial. Epilepsy \& Behavior, 80, 259-265. https://doi.org/10.1016/j.yebeh.2018.01.019

Document status and date:

Published: 01/03/2018

DOI:

10.1016/j.yebeh.2018.01.019

Document Version:

Publisher's PDF, also known as Version of record

Document license:

Taverne

\section{Please check the document version of this publication:}

- A submitted manuscript is the version of the article upon submission and before peer-review. There can be important differences between the submitted version and the official published version of record.

People interested in the research are advised to contact the author for the final version of the publication, or visit the DOI to the publisher's website.

- The final author version and the galley proof are versions of the publication after peer review.

- The final published version features the final layout of the paper including the volume, issue and page numbers.

Link to publication

\footnotetext{
General rights rights.

- You may freely distribute the URL identifying the publication in the public portal. please follow below link for the End User Agreement:

www.umlib.nl/taverne-license

Take down policy

If you believe that this document breaches copyright please contact us at:

repository@maastrichtuniversity.nl

providing details and we will investigate your claim.
}

Copyright and moral rights for the publications made accessible in the public portal are retained by the authors and/or other copyright owners and it is a condition of accessing publications that users recognise and abide by the legal requirements associated with these

- Users may download and print one copy of any publication from the public portal for the purpose of private study or research.

- You may not further distribute the material or use it for any profit-making activity or commercial gain

If the publication is distributed under the terms of Article $25 \mathrm{fa}$ of the Dutch Copyright Act, indicated by the "Taverne" license above, 


\title{
Effectiveness of a multicomponent self-management intervention for adults with epilepsy (ZMILE study): A randomized controlled trial
}

\author{
Loes A.M. Leenen a,b,c,*, Ben F.M. Wijnen ${ }^{\mathrm{a}, \mathrm{b}}$, Alfons G.H. Kessels ${ }^{\mathrm{a}}$, HoiYau Chan ${ }^{\mathrm{a}}$, Reina J.A. de Kinderen ${ }^{\mathrm{g}}$, \\ Silvia M.A.A. Evers ${ }^{\mathrm{a}, \mathrm{g}}$, Caroline M. van Heugten ${ }^{\text {d,f }}$, Marian H.J.M. Majoie ${ }^{\text {b,c,d,e }}$ \\ ${ }^{a}$ Faculty of Health, Medicine and Life Sciences, Department of Health Services Research, CAPHRI Care and Public Health Institute, Maastricht University, Maastricht, The Netherlands \\ ${ }^{\mathrm{b}}$ Department of Research \&' Development, Academic Centre for Epileptology Kempenhaeghe Maastricht UMC + , The Netherlands \\ c Department of Neurology, Academic Centre for Epileptology Kempenhaeghe Maastricht UMC +, The Netherlands \\ d School for Mental Health and Neuroscience (MHENS), Maastricht University Medical Centre, Maastricht, The Netherlands \\ e School of Health Professions Education, Faculty of Health, Medicine and Life Sciences, Maastricht University, Maastricht, The Netherlands \\ ${ }^{\mathrm{f}}$ Faculty of Psychology and Neurosciences: Department of Neuropsychology and Psychopharmacology, Maastricht University, Maastricht, The Netherlands \\ ${ }^{g}$ Trimbos Institute, Netherlands Institute of Mental Health and Addiction, Utrecht, The Netherlands
}

\section{A R T I C L E I N F O}

\section{Article history:}

Received 18 December 2017

Revised 15 January 2018

Accepted 17 January 2018

Available online 12 February 2018

\section{Keywords:}

Epilepsy

Self-management

Self-efficacy

Goal-setting

Multicomponent intervention

Group intervention

PWE \& relative

\begin{abstract}
A B S T R A C T
Background: The objective of the ZMILE study was to compare the effectiveness of a multicomponent selfmanagement intervention ( $\mathrm{MCI}$ ) with care as usual (CAU) in adult patients with epilepsy (PWE) over a six-month period.

Methods: Participants (PWE \& relative) were randomized into intervention or CAU groups.

Self-report questionnaires were used to measure disease-specific self-efficacy as the primary outcome measure and general self-efficacy, adherence, seizure severity, emotional functioning, quality of life, proactive coping, and side-effects of antiepileptic drugs (AED) as secondary outcome measures. Instruments used at baseline and during a six-month follow-up period were the following: disease-specific self-efficacy (Epilepsy Self-Efficacy Scale [ESES], General Self-Efficacy Scale [GSES]); adherence (Medication Adherence Scale [MARS] and Medication Event Monitoring System [MEMS]); seizure severity (National Hospital Seizure Severity Scale [NHS3]); emotional well-being (Hospital Anxiety and Depression Scale [HADS]); quality of life (Quality of Life in Epilepsy [QOLIE-31P]); proactive coping (Utrecht Proactive Coping Competence [UPCC]); and side-effects of antiepileptic drugs [SIDAED]. Multilevel analyses were performed, and baseline differences were corrected by inclusion of covariates in the analyses.

Results: In total, 102 PWE were included in the study, 52 of whom were in the intervention group. On the SIDAED and on three of the quality of life subscales QOLIE-31P, a significant difference was found $(p<0.05)$ in the intervention group. Self-efficacy, however, showed no significant differences between the MCI and the CAU groups. None of the other outcome measures showed any significant difference between the two groups.

Significance: Although we found no statistically significant difference in the primary outcome measure, diseasespecific self-efficacy, this $\mathrm{MCl}$ could prove promising, since we found improvement in some domains of quality of life in epilepsy scale and a decrease in AED side-effects in the MCI group compared with the CAU group.
\end{abstract}

(c) 2018 Elsevier Inc. All rights reserved.

\section{Introduction}

Having epilepsy is associated with psychological and emotional problems, such as depression and anxiety, which are strongly reflected in a reduced quality of life [1,2]. Unpredictable seizures are likely to

\footnotetext{
* Corresponding author at: Academic Centre for Epileptology Kempenhaeghe, Sterkselseweg 65, 5591 VE Heeze, P.O. Box 61, 5590 AB Heeze, The Netherlands.

E-mail addresses: leenenl@kempenhaeghe.nl (L.A.M. Leenen),

b.wijnen@maastrichtuniversity.nl (B.F.M. Wijnen), fons.kessels@maastrichtuniversity.nl (A.G.H. Kessels), h.chan@maastrichtuniversity.nl (H. Chan), RKinderen@trimbos.nl (R.J.A. de Kinderen), s.evers@maastrichtuniversity.nl (S.M.A.A. Evers), c.vanheugten@maastrichtuniversity.nl (C.M. van Heugten), majoiem@kempenhaeghe.nl (M.H.J.M. Majoie)
}

influence daily activities (e.g., employment) of PWE [2]. Thus, as well as managing their symptoms, PWE and their relatives [3] must acquire disease-specific knowledge, adhere to treatment and lifestyle regimes, and cope with the psychosocial consequences of the condition [4,5].

Most PWE use antiepileptic drugs (AED), and concordance is of great importance for achieving and maintaining positive seizure control [6]. Concordance refers to the consensual agreement about taking AED that has been established between patient and practitioner [7]. Poor concordance has been shown to be the most important cause of poorly controlled epilepsy [6]; many PWE seem to be unaware of missed drug intake [8]. To improve concordance, some self-management programs focus on the use of e-Health tools (e.g., digital pill dispensers) [9], although this is not very common in PWE [10]. 
One of the options for increasing concordance could be selfmanagement support for PWE (and relatives) using an evidence-based self-management program, which includes goal-setting, problemsolving, symptom management, and shared decision-making [11-13]. The aim of self-management support is to provide education and supportive interventions to increase skills and confidence in managing health-related problems [12]. Self-efficacy (i.e., confidence to behave with the intention of reaching a desired goal) is one of the mechanisms responsible for improvement in health outcomes and quality of life, as demonstrated by those attending self-management programs $[4,14,15]$. Proactive coping is helpful in dealing with anticipated challenges in order to reach the desired goal [16]. The concept of self-management is complex with many different definitions and conceptualizations and, therefore, many forms of support exist [17]. There is little evidence to prove the effectiveness of self-management programs within the care of PWE [18]. We, therefore, developed a multicomponent intervention $(\mathrm{MCI})$, consisting of a self-management education program with e-Health interventions directed at improving self-efficacy, thus, improving the self-management skills of PWE.

The goal of this study (the ZMILE-study) was to evaluate the clinical effectiveness of the $\mathrm{MCl}$. Our primary expectation was that we would find a higher level of disease-specific self-efficacy in the intervention group compared with those who received CAU. Secondarily, we expected to find higher levels of general self-efficacy, adherence (as a proxy for concordance), and proactive coping. We also expected to find a positive change in seizure severity, emotional functioning, quality of life, and experienced side-effects of AED, these outcome measurements are recommended outcomes in epilepsy research [19].

\section{Method}

\subsection{Design}

The ZMILE-study was a randomized controlled trial with two parallel groups in which we evaluated the impact of the $\mathrm{MCI}$ in comparison with CAU. The complete study protocol has already been published [20]. In this paper, we report the clinical effectiveness. Outcome measurements were assessed at baseline (BS) and at 3 and 6 months' follow-up (FU3M and FU6M). The primary outcome measure of the study was disease-specific self-efficacy; secondary outcomes measures were the following: general self-efficacy, adherence, seizure severity, emotional functioning, quality of life proactive coping, and side-effects of AED. Instruments used to assess outcome measurements are shown in Table 1. The cost-effectiveness and the process evaluation of the ZMILE-study are reported elsewhere [21,22].

\subsection{Participants}

Eligible PWE for this study were adults who were 18 years or over, living at home, diagnosed with epilepsy, and using AED; who understood the Dutch language; and who were willing and able to use e-Health devices belonging to the MCI [20]. Excluded were PWE who were not able or willing to function in group activities, or when, based on clinical judgment, it was considered that they would not be able to comprehend topics discussed within the MCI (e.g., PWE with cognitive deficits). Patients were not selected or referred based on a preexisting measure of epilepsy self-management as this was a pragmatic trial and this more closely resembles actual practice.

\subsection{Procedure}

Between March 2014 and December 2015, the Academic Centre for Epileptology recruited PWE during regular attendances at the neurology clinic, via press releases in national epilepsy magazines (Epilepsie, Transmissie) and via social media (Facebook). All potential candidates were informed about the procedure at an initial meeting with one of the researchers. One week later, PWE who wanted to participate were invited for a second visit, were asked to sign an informed consent form, and were allocated randomly to either the intervention or CAU group.

Baseline measurements (BS) were conducted after randomization. All participants received at baseline the Medication Event Monitoring System (MEMS) and a set of questionnaires. Participants were asked to fill in the questionnaires at home and send them back in a prestamped envelope. Prior to the follow-up visits (FU3M, FU6M), the questionnaires were sent by post so that participants could complete them at home. They were collected during the follow-up visits, and the MEMS was read (i.e., the number of times the container was opened). The procedure was approved by the Ethics Committee of Maastricht University/Hospital Maastricht, The Netherlands; an overview is presented in Fig. 1.

\subsection{Randomization}

To ensure parallel provision of both groups (intervention \& CAU), two equal cohorts of PWEs were needed at the moment of randomization. Patients with epilepsy were assigned to the intervention group or the CAU group by means of block randomization. Instead of the intended blocks of 10 PWE, we also used blocks of six, eight, or ten PWE for practical reasons. An assistant, not involved in the treatment nor in the trial, executed the procedure using a randomization program (www.randomization.com). The randomization scheme was distributed to the researcher in sealed envelopes during the first visit, prior to BS.

Table 1

Overview of measurements per time point.

\begin{tabular}{|c|c|c|c|c|c|}
\hline Outcomes & Instrument & $\begin{array}{l}\text { Range } \\
\text { poor-good }\end{array}$ & BS & FU3M & FU6M \\
\hline \multicolumn{6}{|l|}{ Primary outcome measure } \\
\hline Self-efficacy & Epilepsy Self-efficacy Scale (ESES) [37] & $33-330$ & $\mathrm{X}$ & $\mathrm{X}$ & $\mathrm{X}$ \\
\hline \multicolumn{6}{|c|}{ Secondary outcome measures } \\
\hline General self-efficacy & Generic Self-efficacy Scale (GSES) [38] & $10-40$ & $\mathrm{X}$ & $\mathrm{X}$ & $\mathrm{X}$ \\
\hline Adherence & MEMS [39] & NA & $\mathrm{X}$ & $\mathrm{X}$ & $\mathrm{X}$ \\
\hline Adherence & Medication Adherence Scale (MARS-5) [40] & $5-25$ & $\mathrm{X}$ & $\mathrm{X}$ & $\mathrm{X}$ \\
\hline Seizure frequency & Questionnaire seizure frequency & - & $\mathrm{X}$ & $\mathrm{X}$ & $\mathrm{X}$ \\
\hline Seizure severity $^{\mathrm{a}}$ & National Hospital Seizure Severity Scale (NHS3) [41] & $27-1$ & $\mathrm{X}$ & $\mathrm{X}$ & $\mathrm{X}$ \\
\hline \multirow[t]{3}{*}{ Emotional functioning } & Hospital Anxiety and Depression Scale (HADS) [42] & $42-0$ & $\mathrm{X}$ & $\mathrm{X}$ & $\mathrm{X}$ \\
\hline & Subscale anxiety & $21-0$ & & & \\
\hline & Subscale depression & $21-0$ & & & \\
\hline Quality of life & Quality of Life in Epilepsy (QOLIE-31P) [24,43] & $0-100$ & $\mathrm{X}$ & $\mathrm{X}$ & $\mathrm{X}$ \\
\hline Proactive coping & Utrecht Proactive Coping Competence (UPCC) [44] & $21-84$ & $\mathrm{X}$ & $\mathrm{X}$ & $\mathrm{X}$ \\
\hline Side-effect ${ }^{\mathrm{b}}$ & Side-effects of antiepileptic drugs (SIDAED) [45] & $138-0$ & $\mathrm{X}$ & $\mathrm{X}$ & $\mathrm{X}$ \\
\hline
\end{tabular}

BS = baseline outcome assessments; FU3M \& FU6M = follow-up outcome assessments at 3 \& 6 months.

${ }^{a}$ If no seizures had occurred in the past year, a score of 0 was allocated.

b Only the severity of the side-effects was measured. 


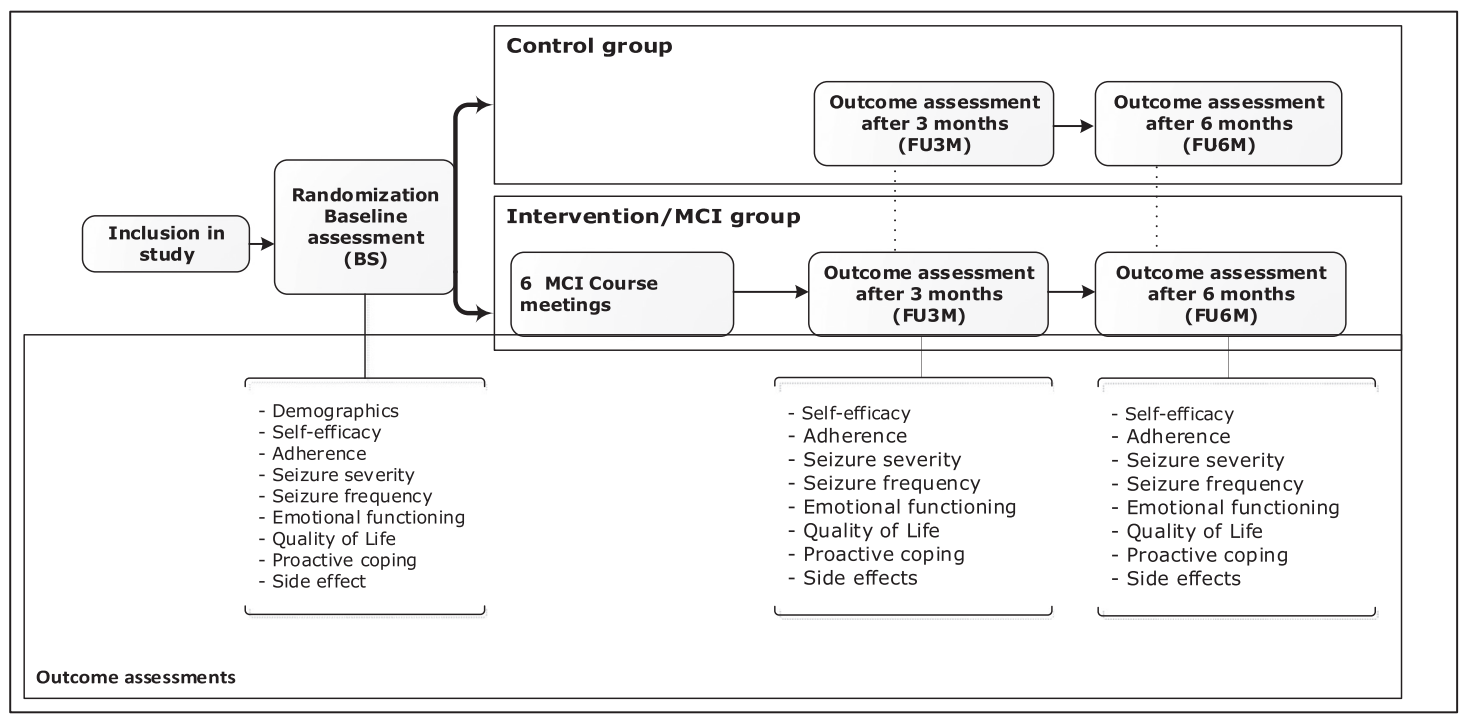

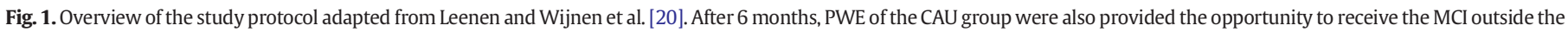
study.

\subsection{Multicomponent intervention}

The MCI consisted of five weekly group sessions of $2 \mathrm{~h}$ each, followed by a two-hour booster session after 3 weeks. The groups comprised three to five PWE with possibly a relative, if present and willing to participate. Sessions led by two nurse practitioners were conducted at several locations in the southern part of the Netherlands (Heeze, Maastricht, and Nijmegen). All group sessions consisted of two components: education and practicing goal-setting skills. In the educational part, participants were sharing and discussing strategies about three topics: 1) self-monitoring and self-monitoring using (e-Health) tools; 2) risk-evaluation and management; and 3) shared decision-making/ concordance. The goal-setting component of the intervention is based on Aspinwall and Taylors' [16] five stages of proactive coping, namely: resource accumulation; recognition of potential stressors; initial appraisal; preliminary coping efforts; and elicitation and use of feedback concerning initial efforts.

The two e-Health tools used for self-monitoring were a Medication Event Monitoring System (MEMS, Aardex) and a smartphone application 'Eppy' (Epilepsy Foundation, the Netherlands). Medication Event Monitoring Systems are electronic caps with an Liquid Crystal Display (LCD) screen, fitting standard pill bottles, that register the date and time the bottle was opened. These data were stored in an internet-based database end presented in simple plots. Additionally, the LCD-screen provides the user with direct feedback on how many times the bottle had been opened that day. Feedback on medication adherence, as collected by MEMS, was given to the intervention group during the group sessions and after 3 and 6 months' follow-up by a nurse practitioner. 'Eppy' is an application that could be downloaded free to a smartphone, giving PWE the opportunity to keep, for instance, a digital seizure diary or to set reminders for taking medication. Data gathered with the Eppy could be synchronized to a website. Access to this website could be granted to healthcare professionals, by the PWE.

A more detailed description of the intervention has been published previously [20,22].

\subsection{Care as usual (CAU)}

The control group received unrestricted CAU. Since the ZMILE-study was a pragmatic trial, the CAU-group did not follow a standardized protocol, thus the content of CAU might be variable across PWE, but is expected to be in agreement with standard epilepsy guidelines (http://epilepsie.neurologie.nl). In order to measure adherence, the CAU group also received the MEMS, but without the LCD screen and without the feedback during the visits.

\subsection{Outcome measurements}

Table 1 presents the questionnaires included in the study. These selfreport questionnaires were used to measure disease-specific selfefficacy as the primary outcome measure and general self-efficacy, adherence, seizure severity, emotional functioning, quality of life, proactive coping, and side-effects of AED as secondary outcome measurements. As the $\mathrm{MCI}$ was based on a self-management program for patients with type 2 diabetes, which was intended to and shown to significantly improve self-efficacy [23], the Epilepsy SelfEfficacy Scale (ESES) was chosen as primary outcome. At baseline, sociodemographic and a limited number of medical variables, such as year of first seizure, were recorded in a patient-reported questionnaire. More details about the administered measurement can be found in the study protocol [20].

The EuroQol-5D-5L was part of the cost-effectiveness study and, therefore, not included in the present study.

\subsection{Sample size E’ analyses}

The required sample size for this study was estimated to be 100 persons (i.e., 50 interventions and $50 \mathrm{CAU}$ ) [20].

All statistical procedures were performed using IBM SPSS statistics version 24 for MacOS, and were based on the intention-to-treat principle. The baseline differences between the MCI group and CAU group were analyzed using independent $t$-tests or Pearson's chi-square tests when appropriate. To compare adherence rates, Wilcoxon rank sum tests were used. The first step in handling missing data was to follow the scoring manual of the ESES and HADS questionnaire [24,25], which prescribes using mean values for handling missing data at item level. The SPSS multiple imputations (five times) were used to manage complete data missing from the ESES and HADS, as well as for data missing from other questionnaires.

Multilevel analyses were performed with outcome measurements (BS, FU3M, and FU6M) as within-subjects' factor and group (intervention or (AU) as between subjects' factors to account for the nested structure (e.g., repeated measures) of the data. Baseline differences were 
corrected by inclusion of covariates in the analyses. Random intercept was used to account for the difference between PWE. A 2-sided significance level of 0.05 was used [26]. In the analysis of the MEMS, PWE were excluded if they did not initiate their MEMS caps.

\section{Results}

\subsection{Participants}

Fig. 2 presents a flowchart showing the path taken by the participants. Overall, 102 PWE took part in the study, of whom 86 completed the trial. All assessments were performed within the schedule of 3 months \pm ( 2 weeks). Although depression is a common comorbidity associated with epilepsy, in this sample, average scores on the HADS did not exceed 6.9 for both anxiety and depression during follow-up. These scores are not above the frequently used cut-off point of 8 to define the presence of depression/anxiety [27]. Table 2 shows the baseline characteristics of the study population.

At baseline, the intervention group had significantly more PWE who were employed $(24 / 50)$ than the CAU group $(11 / 48)(p=.02)$.

\subsection{Clinical effect of the intervention}

Table 3 shows the effects of the intervention. At baseline, the ESES scores of the intervention group were significantly higher than that of the CAU group $(\mathrm{p}=0.02)$.

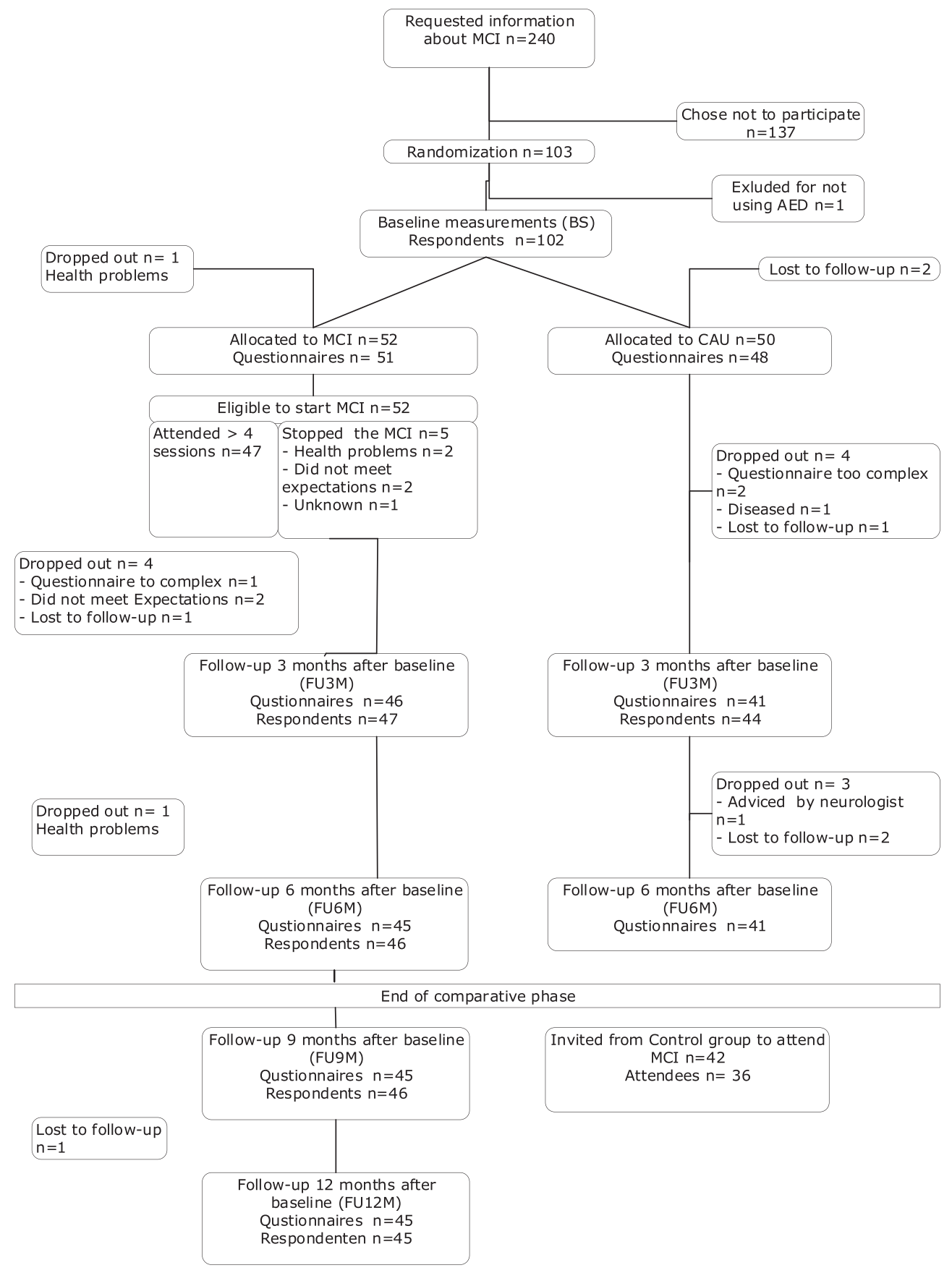

Fig. 2. Flowchart of participants through the study. 
Table 2

(Baseline) characteristics of the population.

\begin{tabular}{|c|c|c|c|}
\hline Characteristics & $\begin{array}{l}\text { Intervention group } \\
(\mathrm{n}=52)\end{array}$ & $\begin{array}{l}\text { CAU group } \\
(\mathrm{n}=50)\end{array}$ & $\begin{array}{l}\text { Total } \\
(\mathrm{n}=102)\end{array}$ \\
\hline \multicolumn{4}{|l|}{ Gender, n (\%) } \\
\hline Male & $28(53.9 \%)$ & $22(44.0 \%)$ & $50(49.0 \%)$ \\
\hline Female & $24(46.2 \%)$ & $28(56.0 \%)$ & $52(51.0 \%)$ \\
\hline Age in years, mean (SD) & $40.0(13.1)$ & $43.5(15.4)$ & $41.7(14.7)$ \\
\hline \multicolumn{4}{|l|}{ Age group, $n(\%)$} \\
\hline $18-24$ & $7(13.5 \%)$ & $7(14.0 \%)$ & $14(13.7 \%)$ \\
\hline $25-44$ & $23(44.2 \%)$ & $20(40.0 \%)$ & $43(42.2 \%)$ \\
\hline $45-64$ & $21(40.4 \%)$ & $18(36.0 \%)$ & $39(38.2 \%)$ \\
\hline$\geq 65$ & $1(1.9 \%)$ & $5(10.0 \%)$ & $6(5.9 \%)$ \\
\hline \multicolumn{4}{|l|}{ Marital status, n (\%) } \\
\hline Married/living with partner & $24(46.1 \%)$ & $28(56.0 \%)$ & $52(51.0 \%)$ \\
\hline Living alone & $15(28.8 \%)$ & $11(22.0 \%)$ & $26(25.5 \%)$ \\
\hline Living with parents & $7(13.5 \%)$ & $8(16.0 \%)$ & $15(14.7 \%)$ \\
\hline Other & $3(5.8 \%)$ & $1(2.0 \%)$ & $4(3.9 \%)$ \\
\hline Missing values & $3(5.8 \%)$ & $2(4.0 \%)$ & $5(4.9 \%)$ \\
\hline \multicolumn{4}{|l|}{ Highest level of education, n (\%) } \\
\hline No education & $2(3.8 \%)$ & $4(8.0 \%)$ & $6(5.9 \%)$ \\
\hline Primary school & $1(1.9 \%)$ & $3(6.0 \%)$ & $4(3.9 \%)$ \\
\hline Prevocational secondary school & $29(55.8 \%)$ & $30(60.0 \%)$ & $59(57.8 \%)$ \\
\hline Secondary school ${ }^{\mathrm{a}}$ & $6(11.5 \%)$ & $3(6.0 \%)$ & $9(8.8 \%)$ \\
\hline Higher education $^{\mathrm{b}}$ & $10(19.2 \%)$ & $5(10.0 \%)$ & $15(14.7 \%)$ \\
\hline Other & $2(3.8 \%)$ & $3(6.0 \%)$ & $5(4.9 \%)$ \\
\hline Missing values & $2(3.8 \%)$ & $2(4 \%)$ & $4(3.9 \%)$ \\
\hline \multicolumn{4}{|l|}{ Daily life, n (\%) } \\
\hline Study & $6(11.5 \%)$ & $3(6.0 \%)$ & $9(8.8 \%)$ \\
\hline Work & $20(38.5 \%)$ & $11(22.0 \%)$ & $31(30.4 \%)$ \\
\hline Entrepreneur & $4(7.7 \%)$ & 0 & $4(3.9 \%)$ \\
\hline Housewife/househusband & $3(5.8 \%)$ & $5(10.0 \%)$ & $8(7.8 \%)$ \\
\hline Unemployed & $9(17.3 \%)$ & $7(14.0 \%)$ & $16(15.7 \%)$ \\
\hline Incapacitated & $5(9.6 \%)$ & $16(32.0 \%)$ & $21(20.6 \%)$ \\
\hline Retirement or early retirement & $2(3.8 \%)$ & $4(8.0 \%)$ & $6(5.9 \%)$ \\
\hline Other & $2(3.8 \%)$ & $2(4.0 \%)$ & $4(3.9 \%)$ \\
\hline Missing values & $1(1.9 \%)$ & $2(4.0 \%)$ & $3(2.9 \%)$ \\
\hline \multicolumn{4}{|l|}{ Employment $^{\mathrm{c}}$} \\
\hline Unpaid job/unemployed & $27(51.9 \%)$ & $36(72.0 \%)$ & $63(61.8 \%)$ \\
\hline Employed & $24(46.2 \%)$ & $11(22.0 \%)$ & $35(34.3 \%)$ \\
\hline Missing values & $1(1.9 \%)$ & $3(6.0 \%)$ & $4(3.9 \%)$ \\
\hline \multicolumn{4}{|l|}{ Medication at baseline, mean (SD) } \\
\hline Total number of medications & $3.5(1.7)$ & $4.2(2.6)$ & $3.8(2.2)$ \\
\hline AED & $1.9(0.9)$ & $2.1(1.0)$ & $2.1(1.0)$ \\
\hline Missing & 3 & 3 & \\
\hline $\begin{array}{l}\text { Seizure frequency at baseline, } \\
\text { mean }(\mathrm{SD})^{\mathrm{d}}\end{array}$ & $4.5(11.0)$ & $5.8(11.3)$ & \\
\hline Missing & 3 & 4 & \\
\hline Years since first seizure, mean (SD) & $20.3(14.2)$ & $19.9(15.8)$ & \\
\hline Missing & 2 & 7 & \\
\hline
\end{tabular}

a Includes: general vocational school, preuniversity school, and secondary vocational education.

b Includes: professional and academic higher education.

c Sig. difference between groups at 5\% level.

d Measured as the total seizures in the past 4 weeks before measurement.

The primary outcome disease-specific self-efficacy showed no significant differences between the MCI and CAU group ( $\mathrm{p}>0.05)$.

Dividing the ESES scores into quartiles (33-107; 108-183; 184-257 and 257-330), we found that most participants gave themselves a score in the third or fourth quartile, i.e., 0/102 in the first, 6/102 in the second, $60 / 102$ in the third, and 36/102 in the fourth quartile.

In total, $49 / 52$ of the intervention and $44 / 50$ of the CAU were included in the analysis. Patients with epilepsy lost to follow-up or who did not use the cap at all, were considered nonadherent. Adherence rates of those included in the MEMS analysis over 6 months were $63.7 \%$ for the CAU group and $75.9 \%$ for the intervention group; the difference was not significant.

There was a significant difference on the side-effect scale SIDAED $(\mathrm{p}=0.04)$, and on three of the subscales of the QOLIE-31P. Subscales 'Emotional wellbeing' ( $p=0.01)$, 'Social functioning' ( $p=0.001$ ), and 'Distress' ( $p=0.01$ ) had a significantly better result in the intervention group. None of the other outcomes, such as quality of life (QOLIE-31P), adherence (MARS), emotional well-being (HADS), seizure severity (NHS3), and proactive coping (UPCC) showed a significant difference between the two groups.

\section{Discussion}

The aim of this study was to evaluate the clinical effectiveness of the $\mathrm{MCI}$ on disease-specific self-efficacy (primary outcome) and on adherence, seizure severity, side-effects of AED, emotional functioning, proactive coping, and quality of life (secondary outcomes). We found higher levels of disease specific self-efficacy in both groups over time, but no significant differences in disease-specific self-efficacy between the intervention and CAU group. On the secondary outcomes, we found significant differences on side-effects and on some subscales of quality of life, but not on the other outcomes i.e., seizure severity, proactive coping, and depression/anxiety. The significant reduction on drug-related side-effects may be contributed the fact that the $\mathrm{MCI}$ focused on patient-physician communication (e.g., How do you prepare a consult?; What do you feel might improve your treatment or what would you like to see changed), which may have led to a more patient-centered AED prescription. However, we have no data available to strengthen this explanation. The significant reduction in subscales of the QOLIE-31P may be explained by the content of the $\mathrm{MCI}$ as some of the domains are specifically discussed during the MCI. For example, participants were expected to work on proactive coping and goalsetting which may have impacted the domain "daily activities", "mood", and "distress".

Not finding a significant difference in (disease-specific) self-efficacy is in contrast to other studies on self-management interventions in epilepsy [28] or other chronic conditions [4,11].

In our study, participants showed a high level of disease-specific self-efficacy at baseline. Only 6/102 scored in the bottom half of the scale and 36/102 in the fourth quartile which could reflect a ceiling effect, leaving little room for improvement [29]. The fact that our participants were volunteers, may have contributed to this ceiling effect [30].

Risdale et al. [31] recently found that self-mastery, adherence, depression, and anxiety are all associated with quality of life in PWE. It is possible that self-mastery did not improve in our study, but we did not measure this concept, although we used the same secondary outcomes; i.e., adherence, depression, anxiety, and quality of life [31]. Probably, our understanding of how the different outcomes interact with each other is, at this moment, insufficient.

In addition, we did not assess changes in self-management behavior, such as goal-attainment, so it remains unclear which components contributed to the potential effect of the intervention; this is not uncommon in complex interventions [32]. Furthermore, the CAU was not standardized and there were some additional attributions (i.e., MEMS and visits). This may have diminished the contrast between the interventions and may, therefore, have influenced the study outcomes [33].

Lastly, in our sample, scores on the HADS-A and HADS-D were relatively low (indicating "no cases"). As shown in a recent overview by the Managing Epilepsy Well network, self-management may have an increased potential in patients with epilepsy who are diagnosed as having additional mental complaints such as depression [34].

Strengths of our study were the low drop-out rate and the limited amount of missing data. Data were analyzed using a mixed model, allowing us to impute missing data. Furthermore, the study population was evenly spread over all age groups.

One of the limitations of our study was the fact that the smartphone application 'Eppy' was not maintained and updated and eventually removed from the App Store (Apple Inc., USA and Google Play store, USA) early in 2015. Therefore, only a small group of the participants were able to use the application without experiencing problems with the system. Secondly, in order not to lose interested PWE during certain periods (e.g., holidays) when recruitment rate was low, we started 
Table 3

Overview of clinical outcomes and significance testing.

\begin{tabular}{|c|c|c|c|c|c|c|}
\hline \multirow[t]{2}{*}{ Measures } & \multicolumn{3}{|c|}{ Intervention group $\mathrm{N}=52$} & \multicolumn{3}{|c|}{ Care as usual $\mathrm{N}=50$ ) } \\
\hline & BS & FU3M & FU6M & BS & FU $3 \mathrm{M}$ & FU $6 \mathrm{M}$ \\
\hline \multicolumn{7}{|l|}{ Primary, mean (SD) } \\
\hline \multicolumn{7}{|l|}{ Self-efficacy } \\
\hline Epilepsy Self-Efficacy Scale & $243.8^{\mathrm{a}}(23.3)$ & $253.2(30.4)$ & $263.2(26.3)$ & $230.4^{\mathrm{a}}(32.3)$ & $244.7(32.1)$ & $252.3(32.8)$ \\
\hline \multicolumn{7}{|l|}{ Secondary, mean (SD) } \\
\hline \multicolumn{7}{|l|}{ Self-efficacy } \\
\hline General Self-Efficacy Scale & $29.4(5.8)$ & $31.5(5.2)$ & $31.7(4.6)$ & $27.9(5.6)$ & $29.3(5.1)$ & $30.0(5.4)$ \\
\hline \multicolumn{7}{|l|}{ Adherence } \\
\hline Medication Event monitoring System (MEMS) & & & $75.9 \%(32.5)$ & & & $63.7 \%(36.6)$ \\
\hline Medication Adherence Rating Scale (MARS) & $23.4(2.0)$ & $23.6(1.4)$ & $23.9(0.9)$ & $23.8(1.1)$ & $23.9(1.1)$ & $23.7(1.3)$ \\
\hline \multicolumn{7}{|l|}{ Seizure severity } \\
\hline National Hospital Seizure Severity Scale (NHS3) & $6.7(7.5)$ & $7.3(8.1)$ & $6.2(7.3)$ & $9.0(9.6)$ & $8.4(9.3)$ & $8.7(10.0)$ \\
\hline \multicolumn{7}{|l|}{ Depression/anxiety } \\
\hline Hospital Anxiety and Depression Scale (HADS) - total & $11.3(6.1)$ & $11.0(5.2)$ & $9.8(5.0)$ & $12.7(5.9)$ & $11.5(6.2)$ & $11.6(6.2)$ \\
\hline HADS - depression & $5.3(2.6)$ & $5.7(2.7)$ & $5.2(2.6)$ & $5.7(2.3)$ & $5.5(2.6)$ & $5.5(2.8)$ \\
\hline HADS - anxiety & $5.9(4.3)$ & $5.2(3.5)$ & $4.7(3.5)$ & $6.9(4.3)$ & $6.1(4.2)$ & $6.0(4.2)$ \\
\hline \multicolumn{7}{|l|}{ Quality of life } \\
\hline Quality of Life in Epilepsy-31 (QOLIE-31P) - total & $66.44(12.3)$ & $69.0(11.3)$ & $69.5(10.8)$ & $62.9(12.4)$ & $62.4(14.8)$ & $65.4(14.4)$ \\
\hline \multicolumn{7}{|l|}{ Subscales } \\
\hline QOLIE-31P - energy & $41.4(23.8)$ & $46.3(23.4)$ & $47.8(22.0)$ & $37.8(22.1)$ & $42.1(26.1)$ & $40.2(23.7)$ \\
\hline QOLIE-31P - mood ${ }^{\mathrm{a}}$ & $51.7(23.8)$ & $53.7(28.4)$ & $62.0(23.1)$ & $45.4(25.5)$ & $47.8(29.5)$ & $49.0(27.9)$ \\
\hline QOLIE-31P - daily activities ${ }^{\mathrm{a}}$ & $39.1(26.9)$ & $49.1(27.4)$ & $55.5(29.1)$ & $36.4(25.1)$ & $40.2(26.7)$ & $39.7(25.9)$ \\
\hline QOLIE-31P - cognition & $35.4(23.9)$ & $50.2(27.6)$ & $44.8(23.6)$ & $32.0(28.0)$ & $36.5(30.2)$ & 39.7 (25.9) \\
\hline QOLIE-31P - medication effects & $51.6(30.6)$ & $56.4(25.7)$ & $57.9(27.6)$ & $43.2(27.2)$ & $51.9(29.0)$ & $45.2(25.2)$ \\
\hline QOLIE-31P - seizure worry & $47.5(31.2)$ & $54.0(28.3)$ & $53.9(26.4)$ & $39.3(26.8)$ & $43.9(29.8)$ & $42.8(32.7)$ \\
\hline QOLIE-31P - overall quality of life & $51.1(22.8)$ & $54.4(24.3)$ & $58.8(22.4)$ & $44.8(23.2)$ & $48.0(27.7)$ & $46.7(27.2)$ \\
\hline QOLIE-31P - distress ${ }^{\mathrm{a}, \mathrm{b}}$ & $462.8(128.9)$ & $510.4(129.9)$ & $534.6(101.6)$ & $423.7(142.2)$ & $457.1(148.9)$ & $442.9(156.0)$ \\
\hline \multicolumn{7}{|l|}{ Proactive coping } \\
\hline Utrecht Proactive Coping Competence (UPCC) & $62.6(11.1)$ & $62.5(8.5)$ & $64.0(9.0)$ & $59.7(6.7)$ & $60.3(7.9)$ & $61.1(7.5)$ \\
\hline \multicolumn{7}{|l|}{ Side-effects } \\
\hline Side-effects of antiepileptic drugs (SIDAED) ${ }^{a}$ & $26.9(21.6)$ & $23.1(18.7)$ & $19.1(15.3)$ & $27.1(20.3)$ & $26.2(17.6)$ & $25.5(19.1)$ \\
\hline
\end{tabular}

block randomization at a minimum of six PWE; this was a deviation from the protocol.

Finally, our sample size was based on a standard deviation of 7 points on the ESES. In this study, we found a standard deviation of $>30$ points. The decrease in study power might have resulted in failure to detect statistically significant findings.

We acknowledge that further research is necessary to establish the overall effectiveness of the MCI. This should take its place alongside process evaluation and economic evaluation of the intervention, both of which showed more favorable outcomes $[21,22]$. The neurologists who recruited participants believed the intervention to be fruitful for both PWE and neurologist: the former showing more confidence and being prepared, and the latter experiencing a more effective consultation time; this was, however, not measured in this study.

A recently developed instrument for measuring the effectiveness of self-management interventions in epilepsy, the Adult Epilepsy SelfManagement Measurement Instrument (AESMMI), may prove to be a great addition to future research. The AESMMI provides an overall effectiveness measure for self-management interventions in epilepsy [35] and is a synthesis of 11 instruments, including the ESES and the QOLIE-31P.

We did not measure mastery, a concept that one can control options/ events in life [36]. Mastery experiences are the most effective way of becoming more self-efficacious [14] and are associated with quality of life and emotional functioning [31]. Hence, this would seem to be an important concept to measure in future research.

In conclusion, in spite of the lack of evidence that the $\mathrm{MCI}$ is effective looking at self-efficacy, we consider the $\mathrm{MCI}$ to be a promising intervention, because of the reduction of side-effects and on improving quality of life on subscales. Further research is needed, but we believe it should be carried out alongside implementation in order to reach a larger group of PWE. We recommend focusing on mastery and the domains of self-management as measured with the AESMMI, as they include most of the well-established outcome measures in epilepsy research (i.e., quality of life, adherence, side-effects, emotional functioning).

\section{Competing interests}

The authors declare that they have no competing interests.

\section{Acknowledgments}

We would like to thank Our Advisory board for their contribution to the study: Drs. C. Caron (The Netherlands Epilepsy Foundation; Epilepsie Vereniging Nederland; EVN), M.K.H. van Kan-Sieswerda (EVN), Dr. R.H.C. Lazeron (Kempenhaeghe), Drs. I.Y. Tan (Kempenhaeghe), Drs. C.I. Vader (Kempenhaeghe), Dr. A. Pieron (UCB Pharma), Dr. L. Hageman (UCB Pharma), Drs. A. Lenssen (CZ Health Insurance; Centraal Ziekenfonds), and Dr. B. Vrijens (AARDEX Ltd.). Furthermore, we would like to thank Mrs. Vollers for correcting grammatical and spelling errors, Mrs. J. Lambermont for editing the questionnaires.

This study was funded by the Netherlands Organization for Health Research and Development (ZonMw), grant application number 836011018. This study is registered with the Dutch Trial Register, part of the Dutch Cochrane Centre (NTR4484), and has been approved by the Ethics Committee of Maastricht University/Hospital Maastricht. The Netherlands

\section{References}

[1] Taylor RS, Sander JW, Taylor RJ, Baker GA. Predictors of health-related quality of life and costs in adults with epilepsy: a systematic review. Epilepsia 2011;52(12): 2168-80. https://doi.org/10.1111/j.1528-1167.2011.03213.x.

[2] Baker GA. The psychosocial burden of epilepsy. Epilepsia 2002;43(Suppl. 6):26-30. 
[3] Ryan P, Sawin KJ. The Individual and Family Self-Management Theory: background and perspectives on context, process, and outcomes. Nurs Outlook 2009;57(4): 217-25 e6. https://doi.org/10.1016/j.outlook.2008.10.004.

[4] Bodenheimer T, Lorig K, Holman H, Grumbach K. Patient self-management of chronic disease in primary care. JAMA 2002;288(19):2469-75.

[5] Faber M, Harmsen M, van der Burg S, van der Weijden T. Gezamenlijke besluitvorming \& Zelfmanagement: Een literatuuronderzoek naar de effectiviteit ven en naar voorwaarden voor succes. Nijmegen: Scientific Institute for Quality of Healthcare (IQ healthcare); 2013. https://www.raadrvs.nl/uploads/docs/ Achtergrondstudie_Gezamenlijkebesluitvorming_en_Zelfmanagement.pdf [Accessed 01 August 2017].

[6] Jones RM, Butler JA, Thomas VA, Peveler RC, Prevett M. Adherence to treatment in patients with epilepsy: associations with seizure control and illness beliefs. Seizure 2006;15(7):504-8.

[7] Haynes RB, Ackloo E, Sahota N, McDonald HP, Yao X. Interventions for enhancing medication adherence. Cochrane Database Syst Rev 2008;2:CD000011. https://doi.org/10. 1002/14651858.CD000011.pub3.

[8] Samsonsen C, Reimers A, Bråthen G, Helde G, Brodtkorb E. Nonadherence to treatment causing acute hospitalizations in people with epilepsy: an observational, prospective study. Epilepsia 2014;55(11):e125-e8. https://doi.org/10.1111/epi. 12801.

[9] Demonceau J, Ruppar T, Kristanto P, Hughes DA, Fargher E, Kardas P, et al. Identification and assessment of adherence-enhancing interventions in studies assessing medication adherence through electronically compiled drug dosing histories: a systematic literature review and meta-analysis. Drugs 2013;73(6): 545-62. https://doi.org/10.1007/s40265-013-0041-3.

[10] Leenen LA, Wijnen BF, de Kinderen RJ, van Heugten CM, Evers SM, Majoie MH. Are people with epilepsy using eHealth-tools? Epilepsy Behav 2016;64(Pt A):268-72 https://doi.org/10.1016/j.yebeh.2016.08.007.

[11] Lorig KR, Ritter PL, Laurent DD, Plant K. Internet-based chronic disease selfmanagement: a randomized trial. Med Care 2006;44(11):964-71. https://doi.org/ 10.1097/01.mlr.0000233678.80203.c1.

[12] England MJ, Liverman CT, Schultz AM, Strawbridge LM. Epilepsy across the spectrum: promoting health and understanding. A summary of the Institute of Medicine report. Epilepsy Behav 2012;25(2):266-76. https://doi.org/10.1016/j. yebeh.2012.06.016

[13] Amir M, Roziner I, Knoll A, Neufeld M. Self-efficacy and social support as mediators in the relation between disease severity and quality of life in patients with epilepsy. Epilepsia 1998;40(2):216-24

[14] Benight CC, Bandura A. Social cognitive theory of posttraumatic recovery: the role of perceived self-efficacy. Behav Res Ther 2004;42(10):1129-48. https://doi.org/10. 1016/j.brat.2003.08.008.

[15] Pramuka M, Hendrickson R, Zinski A, Van Cott AC. A psychosocial self-management program for epilepsy: a randomized pilot study in adults. Epilepsy Behav 2007; 11(4):533-45. https://doi.org/10.1016/j.yebeh.2007.06.013.

[16] Aspinwall LG, Taylor SE. A stitch in time: self-regulation and proactive coping. Psychol Bull 1997;121(3):417-36. https://doi.org/10.1037/0033-2909.121.3.417.

[17] de Silva D. Evidence: helping people help themselves - a review of the evidence considering whether it is worthwhile to support self-management. Londen: Health Foundation; 2011. http://www.health.org.uk/publication/evidence-helping-peoplehelp-themselves, Accessed date: 16 August 2017.

[18] Shegog R, Bamps YA, Patel A, Kakacek J, Escoffery C, Johnson EK, et al. Managing Epilepsy Well: emerging e-tools for epilepsy self-management. Epilepsy Behav 2013; 29(1):133-40. https://doi.org/10.1016/j.yebeh.2013.07.002.

[19] Ben-Menachem E, Biton V, Jatuzis D, Abou-Khalil B, Doty P, Rudd GD. Efficacy and safety of oral lacosamide as adjunctive therapy in adults with partial-onset seizures. Epilepsia 2007:48(7):1308-17. https://doi.org/10.1111/j.1528-1167.2007.01188x.

[20] Leenen LA, Wijnen BF, de Kinderen RJ, Majoie MH, van Heugten CM, Evers SM. (Cost)effectiveness of a multi-component intervention for adults with epilepsy: study protocol of a Dutch randomized controlled trial (ZMILE study). BMC Neurol 2014; 14(1471-2377 (Electronic)):255. https://doi.org/10.1186/s12883-014-0255-3.

[21] Wijnen BFM, Leenen LAM, de Kinderen RJA, van Heugten CM, Majoie M, Evers S. An economic evaluation of a multicomponent self-management intervention for adults with epilepsy (ZMILE study). Epilepsia 2017;58(8):1398-408. https://doi.org/10. 1111/epi.13806.

[22] Leenen LAM, Wijnen BFM, van Haastregt JCM, de Kinderen RJA, Evers S, Majoie M, et al. Process evaluation of a multi-component self-management intervention for adults with epilepsy (ZMILE study). Epilepsy Behav 2017;73:64-70. https://doi.org/ 10.1016/j.yebeh.2017.05.023.

[23] Thoolen B, de Ridder D, Bensing J, Gorter K, Rutten G. Beyond Good Intentions: the development and evaluation of a proactive self-management course for patients recently diagnosed with type 2 diabetes. Health Educ Res 2008;23(1):53-61. https://doi.org/10.1093/her/cyl160.

[24] Cramer JA, Van Hammee G, Group NS. Maintenance of improvement in healthrelated quality of life during long-term treatment with levetiracetam. Epilepsy Behav 2003;4(2):118-23.

[25] Bell ML, Fairclough DL, Fiero MH, Butow PN. Handling missing items in the Hospital Anxiety and Depression Scale (HADS): a simulation study. BMC Res Notes 2016; 9(1):479. https://doi.org/10.1186/s13104-016-2284-z.

[26] Field A. Discovering statistics using SPSS. Sage Publications; 2009.

[27] Bjelland I, Dahl AA, Haug TT, Neckelmann D. The validity of the Hospital Anxiety and Depression Scale. An updated literature review. J Psychosom Res 2002;52(2):69-77.

[28] Dilorio C, Escoffery C, McCarty F, Yeager KA, Henry TR, Koganti A, et al. Evaluation of WebEase: an epilepsy self-management Web site. Health Educ Res 2009;24(2): 185-97. https://doi.org/10.1093/her/cyn012.

[29] Wang L, Zhang Z, McArdle JJ, Salthouse TA. Investigating ceiling effects in longitudinal data analysis. Multivar Behav Res 2009;43(3):476-96. https://doi.org/10.1080/ 00273170802285941.

[30] Tarquinio C, Kivits J, Minary L, Coste J, Alla F. Evaluating complex interventions: perspectives and issues for health behaviour change interventions. Psychol Health 2015;30(1):35-51. https://doi.org/10.1080/08870446.2014.953530.

[31] Risdale L, Wojewodka G, Robinson E, Landau S, Noble A, Taylor S, et al. Characteristics associated with quality of life among people with drug-resistant epilepsy. J Neurol 2017;264(6):1174-84. https://doi.org/10.1007/s00415-017-8512-1.

[32] Craig P, Dieppe P, Macintyre S, Michie S, Nazareth I, Petticrew M, et al. Developing and evaluating complex interventions: the new Medical Research Council guidance. BMJ 2008;337. https://doi.org/10.1136/bmj.a1655.

[33] Ayling K, Brierley S, Johnson B, Heller S, Eiser C. How standard is standard care? Exploring control group outcomes in behaviour change interventions for young people with type 1 diabetes. Psychol Health 2015;30(1):85-103. https://doi.org/ 10.1080/08870446.2014.953528.

[34] Sajatovic M, Jobst BC, Shegog R, Bamps YA, Begley CE, Fraser RT, et al. The Managing Epilepsy Well Network: advancing epilepsy self-management. Am J Prev Med 2017; 52(3, Supplement 3):S241-S5. https://doi.org/10.1016/j.amepre.2016.07.026.

[35] Escoffery C, Bamps Y, LaFrance Jr WC, Stoll S, Shegog R, Buelow J, et al. Factor analyses of an Adult Epilepsy Self-Management Measurement Instrument (AESMMI). Epilepsy Behav 2015;50:184-9. https://doi.org/10.1016/j.yebeh.2015.07.026.

[36] Pearlin LI, Schooler C. The structure of coping. J Health Soc Behav 1978;19(1):2-21.

[37] Dilorio C, Faherty B, Manteuffel B. The development and testing of an instrument to measure self-efficacy in individuals with epilepsy. J Neurosci Nurs 1992;24(1):9-13.

[38] Scholz U, Gutiérrez Doña B, Sud S, Schwarzer R. Is General Self-Efficacy a Universal Construct?1. European Journal of Psychological Assessment 2002;18(3):242-51.

[39] Jones RM, Butler JA, Thomas VA, Peveler RC, Prevett M. Adherence to treatment in patients with epilepsy: Associations with seizure control and illness beliefs. Seizure 2006;15(7):504-8.

[40] Menckeberg TT, Bouvy ML, Bracke M, Kaptein AA, Leufkens HG, Raaijmakers JA, Horne R. Beliefs about medicines predict refill adherence to inhaled corticosteroids. J Psychosom Res 2008;64(1):47-54.

[41] O'Donoghue MF, Sander JW, Duncan JS. The National Hospital Seizure Severity Scale: a further development of the Chalfont Seizure Severity Scale. Epilepsia 1996;37(6): 563-71.

[42] Zigmond AS, Snaith RP. The hospital anxiety and depression scale. Acta psychiatrica scandinavica 1983;67(6):361-70.

[43] Devinsky O, Vickrey BG, Cramer J, Perrine K, Hermann B, Meador K, Hays RD. Development of the quality of life in epilepsy inventory. Epilepsia 1995;36(11):1089-104.

[44] Bode C, Thoolen B. Ridder d: Het meten van proactieve copingvaardigheden. Psychologie \& gezondheid 2008;36(2):81-91.

[45] Uijl SG, Uiterwaal CS, Aldenkamp AP, Carpay JA, Doelman JC, Keizer K, Vecht CJ, de Krom MC, van Donselaar CA. A cross-sectional study of subjective complaints in patients with epilepsy who seem to be well-controlled with anti-epileptic drugs. Seizure 2006;15(4):242-8. 